\title{
Symposium
}

\section{Hepatic abscesses}

\author{
Brig S. Rajagopalan ${ }^{a, *}$, Col V. Langer ${ }^{b}$ \\ ${ }^{a}$ Professor \& HOD, Department of Surgery, AFMC, Pune 411 040, India \\ ${ }^{\mathrm{b}}$ Associate Professor, Department of Surgery, AFMC, Pune 411 040, India
}

Keywords:

Pyogenic abscess

Amoebic abscess

Percutaneous drainage

\begin{abstract}
A B S T R A C T
Hepatic abscesses are potentially lethal diseases if early diagnosis and treatment are not instituted. They are prevalent all over the globe and pyogenic abscesses are predominant over amoebic. With better control of intra abdominal and systemic infections by a spectrum of antibiotics, aetiology of pyogenic abscesses are secondary to interventions and diseases in the biliary tree to a large extent today. The common organisms isolated are the Gram negative group. Amoebic abscesses continue to plague some regions of the world where hygiene and sanitation are questionable.

Over the years, diagnosis, treatment and prognosis have evolved remarkably. Imaging modalities like ultrasonography and CT scan have become the cornerstone of diagnosis. The absence of ionizing radiation makes MRI an attractive alternative in patients who require multiple follow up scans. Serological testing in amoebic abscesses has become more reliable. Though antibiotics have remained the principal modality of management, percutaneous drainage of abscesses have vastly improved the chances of cure and bring down the morbidity drastically in pyogenic abscesses. Amoebic abscesses respond well to medical treatment with nitroimidazoles, and minimally invasive surgical drainage is an option in cases where open surgery is indicated.
\end{abstract}

(c) 2012, Armed Forces Medical Services (AFMS). All rights reserved.

\section{Introduction}

Liver abscesses are relatively uncommon in the Western countries, but in India and the Asian countries, they continue to present in the outpatient with regularity. Though the mortality has considerably decreased, the morbidity and associated loss of man hours are a concern. With increase in incidence of immunosuppression following organ transplantation, AIDS, diabetes and cirrhosis there is a progressive rise in fungal and mycobacterial abscesses adding a new dimension to the problem.

\section{Types}

(a) Pyogenic - nonspecific bacterial, mycobacterial, fungal

(b) Amoebic.

\section{Pyogenic abscess}

\section{Demographics}

In the West, there is an increasing trend in pyogenic hepatic abscesses probably due to rise in incidence of hepatobiliary

\footnotetext{
* Corresponding author.

E-mail address: rajdel17@hotmail.com (S. Rajagopalan). 0377-1237/\$ - see front matter (c 2012, Armed Forces Medical Services (AFMS). All rights reserved. doi:10.1016/j.mjafi.2012.04.006
} 
disorders though there has been a corresponding decrease in incidence of intra abdominal infections which was the primary cause two decades ago. So also, the age incidence has shifted from young adults to average ages in the fifth to sixth decades of life. ${ }^{1,2}$

\section{Aetiopathogenesis}

\section{Routes}

Most common route of infection is the biliary tract. Malignancy in the biliary tree causing obstruction, cholangitis and abscess formation is common in the Western population and in the East, it is due to choledocholithiasis. Increasing use of stents in the bile duct is emerging as a common cause in most parts of the World today. Prior biliary surgery like hepaticojejunostomy ${ }^{3}$ and parasitic infestations like ascariasis form a small part of the incidence, though Malik et al in a retrospective study of 169 patients over a 5 - year period in a tertiary care center in Kashmir had an incidence of $17.75 \%$ of ascariasis causing liver abscesses. ${ }^{4}$

Portal venous transmission of infection from the abdomen appendicitis, diverticulitis, cancer colon, inflammatory bowel disease etc - continues to remain an important route.

Systemic bacteraemic infections has the potential to seed the liver through the hepatic artery from infected cardiac valves, endocarditis, IV drug users, pneumonitis, osteomyelitis apart from transarterial procedures like chemoembolization and radiofrequency ablation of malignancies. ${ }^{5,6}$

Direct spread of infection from nearby sources like subphrenic and pyonephric abscesses, pyocele of gall bladder and so on do occur. Secondary infection of parasitic cysts is not uncommon in some parts of Central Asia and India.

Trauma due to penetrating injuries or infection of a haematoma following a blunt injury remains a likely cause.

In upto $20 \%$ of cases, even after detailed investigations, abscesses are found to be cryptogenic ${ }^{7}$ especially in diabetics, cirrhotics and the immunocompromised.

\section{Organisms}

E coli and Klebsiella ${ }^{8}$ are the commonest isolated organisms followed by staphylococcus aureus, enterococcus, streptococcus and bacteroides. Mycobacterium and fungal growths are extremely rare.

\section{Presentation}

Fever and chills are the most frequent presenting symptoms in almost $92-99 \%$ cases, ${ }^{9,10}$ followed by abdominal pain (67\%) in adults. ${ }^{8}$ In children, almost $89 \%{ }^{11}$ have abdominal pain. Jaundice (25\%), hepatomegaly, systemic manifestations like nausea, vomiting, malaise, weight loss and rarer symptoms referable to the respiratory system and features of peritonitis and generalized sepsis are encountered.

\section{Laboratory investigations}

Leucocytosis and mild anaemia is a constant feature. Amongst the liver function tests, rise in alkaline phosphatase in upto $80 \%$ cases and hyperbilirubinaemia and raised transaminases in almost $50 \%$ cases is seen. Blood cultures are positive in $50-60 \%$ cases. $^{1}$

\section{Imaging}

Chest $\mathrm{X}$ rays

Non specific abnormalities are found in $50 \%$ cases. ${ }^{12}$ Elevated hemidiaphragm, pneumonitis, atelectasis or effusion either unilaterally or bilaterally is noticed.

\section{Ultrasonography abdomen}

Lesions $>2 \mathrm{cms}$ are picked up easily.

\section{CT scan}

Hypodense, cystic lesions $>0.5 \mathrm{cms}$, with distinct wall enhancement with or without 'clusters' of smaller abscesses all around are seen. ${ }^{13}$

\section{MRI}

has no distinct advantage over CT scan or USG. ${ }^{14}$

\section{Treatment options}

Treatment in pyogenic abscesses have to be tailored to each patient and some may even require long periods of ICU care, ${ }^{15}$ though majority can be treated with antibiotics and percutaneous methods. Management modalities do not differ in the paediatric population as concluded in a retrospective study by Mishra et al. $^{16}$ The options available are

(a) Antibiotics alone

(b) Antibiotics in combination with

(a) Closed aspiration

(b) Percutaneous catheter drainage

(c) Surgical drainage - open or laparoscopic

\section{Antibiotics}

These form the mainstay of treatment. A combination of two or more broad spectrum antibiotics that cover both Gram positive and negative organisms, keeping in mind the primary pathology causing the abscesses, are given intravenously. They may have to be exhibited for 2-3 weeks based on the response and therefore needs to be individualized. Metronidazole is added as there is always the possibility of bacteroides or other anaerobic organisms.

\section{Closed aspiration}

Commonly USG guided aspiration is the modality for small abscesses. Some of them may require multiple aspirations. The advantages include not only the possibility of complete evacuation thus favouring better antibiotic action but also help in using culture based antibiotics. Aspiration is avoided in ascitis, coagulopathy and proximity of abscesses to vital structures.

\section{Percutaneous catheter drainage}

This is a better option for larger abscesses though the success rate for both these techniques is in the range of $60-90 \%$ in various studies. Mezhir ${ }^{17}$ in his study of 58 patients required 
open surgery in only 5 patients, but performed percutaneous drainage in 38 cases. This is particularly advantageous since there is a possibility of reaccumulation of pus after closed aspiration and more than one attempt may be needed if aspiration only is resorted to.

However, a 2003 prospective, randomised trial in patients pretreated with antibiotics were subjected to needle aspiration or percutaneous catheter drainage and no statistically significant outcome was noticed in both the arms of the study. ${ }^{18}$ Hence both the methods are equally effective in those not requiring operative intervention for other coexisting problems. Pang et al in a 10 - year retrospective study also conclude that IV antibiotics coupled with drainage is the best modality. ${ }^{19}$

\section{Surgical drainage}

We have now moved on from extraperitoneal to intraperitoneal drainage due to the availability of excellent antibiotics. Indications are failed medical therapy, failed aspiration/ percutaneous catheter drainage and left lobe abscesses. Approach could be open or laparoscopic, therapeutic result is the same and biliary pathology can be simultaneously tackled. ${ }^{20}$

\section{Outcome}

In spite of the best efforts, late presentations especially in the elderly, immunocompromised, diabetes, malignancy, sepsis, organ failure, hypoalbuminaemia and abscess rupture are the reasons for the mortality to hover around the $10 \%$ mark. Chen et $\mathrm{al}^{21}$ argue that severity of the disease as measured by APACHE II and SAP II (simplified acute physiology) scores are excellent predictors of mortality.

\section{Amoebic abscess}

\section{Demographics}

Amoebic liver abscesses, once uncommon in the West, now show a rise in incidence due to increasing international travel and immigration into the West by Eastern races. Traditionally, incidence has been high in India, Mexico, Central and Southern America and countries of South African continent. This is explained due to the poor hygiene and sanitation, lack of clean drinking water and absence of health education. However, this is undergoing a change and a perceptible fall is being noticed in the last decade. There is a preponderance of this disease in males with a male: female ratio of as high as 10: 1 in some studies. Age incidence is high in young adults less than 40 years.

\section{Aetiopathogenesis}

Entamoeba histolytica, the causative organism of amoebiasis, continues to be a nuisance to humanity. It exists both in the vegetative (trophozoite) and cyst forms in the humans. The quadrinucleate cysts ingested with contaminated food or water being resistant to gastric juice settles down in the mucosa of large bowel after excystation. The trophozoites bury into the mucosa and create flask shaped ulcers. They may cause typical amoebic dysenteric stools in the weak host and atypical diarrhoeas in the resistant. They enter the liver via the portal circulation and cause hepatic abscesses, spread to the systemic circulation thereafter and cause abscesses elsewhere or may revert back to the cyst phase and get excreted in the stools to reinfect fresh hosts by the faecal oral route.

In the liver they quickly cause liquefactive necrosis leading to a large abscess cavity with a preference for the right lobe [probably due to the laminar flow to the right lobe. ${ }^{22}$ Abscesses typically contain 'anchovy sauce' pus and are often single. ${ }^{23}$

\section{Presentation}

Almost all patients have right upper quadrant pain with or without fever and chills. About 25\% present with jaundice. Onset could be acute (abscess and diarrhea presenting together) or chronic. A general feeling of malaise, low grade fever and anorexia is a fairly common presentation. Tender hepatomegaly and anaemia may be seen. It is often difficult to separate amoebic from pyogenic abscess from history and examination alone.

\section{Complications}

Rupture is the only complication and is often into the peritoneal cavity, thus raising the morbidity and mortality. Pleuropulmonary rupture is less frequently seen, and in abscesses close to the dome. Rare ruptures into the pericardial cavity are reported and need urgent aspiration. Left sided abscesses may rupture into hollow viscera.

\section{Laboratory investigations}

Alteration in blood biochemistry is often non specific with leucocytosis and anaemia being a most common finding. Liver function test may be deranged with raised serum alkaline phosphatase levels ${ }^{24}$ and sometimes transaminases. Prothrombin time may be elevated. Stool examination for trophozoites and cysts are often negative.

\section{Serology}

Several serological studies directed against entamoeba histolytica antigens are useful aids in diagnosis. Currently ELISA and indirect haemagglutination tests appear to be the most reliable and sensitive. ${ }^{25}$

\section{Imaging}

Chest $\mathrm{X}$ rays

In many cases, either unilateral or bilateral pneumonitis, atelectasis or effusion is noticed.

\section{Ultrasonography abdomen}

Lesions $>2 \mathrm{cms}$ are picked up easily, most useful and commonly used tool with accuracy of upto $80 \%$. Sensitivity is in about $96 \%{ }^{26}$ 


\section{CT scan}

Hypodense, cystic lesions $>0.5 \mathrm{cms}$, often solitary, with distinct wall enhancement are seen.

\section{MRI}

has no distinct advantage over CT scan.

\section{Treatment options}

(a) Anti amoebic drugs - Nitroimidazoles and other luminal amoebicides

(b) Nitroimidazoles in combination with luminal amoebicides and
(a) Closed aspiration
(b) Percutaneous catheter drainage
(c) Surgical drainage - open or laparoscopic

\section{Nitroimidazoles}

Metronidazole is the drug of choice given in the dose of $750 \mathrm{mg}$ IV 8th hourly for at least 10-14 days. Other imidazoles like Ornidazole, Secnidazole and Tinidazole have been used with success. On imaging, closure or collapse of the cavity may take as long as one to two years or even longer. Hence the end point of treatment remains disappearance of symptoms and signs.

In all cases, a course of luminal amoebicide like Diloxanide furoate $500 \mathrm{mg}$ 8th hourly to take care of the trophozoites are advocated. Paromomycin and iodoquinols are suitable alternatives. Conservative medical management of uncomplicated liver abscesses is safe and patients who fail medical therapy need aspiration. ${ }^{27,28}$

\section{Aspiration and drainage}

The role of aspiration and drainage is minimal. The indications being clinical absence of improvement or deterioration during medical treatment, secondary bacterial infection or suspected pyogenic abscess, or an impending abscess rupture. Open or laparoscopic drainage is offered only in large left lobe abscesses and in the possibility of rupture. Care must be taken when dividing septa within the abscess as these can be blood vessels or biliary radicles whose disruption can lead to haemorrhage or post operative bile leaks. After thorough wash and suction, drains may be used. ${ }^{29}$

\section{Outcome}

Several patient factors have been associated with poor outcomes. These factors found significant in a logistical regression analysis were a bilirubin $>3.5 \mathrm{mg} / \mathrm{dl}$, albumin $<2.0 \mathrm{~g} / \mathrm{dl}$, encephalopathy, volume of abscess cavity $>500 \mathrm{ml}$, and the number of abscesses. ${ }^{30}$

\section{Conclusion}

Hepatic abscesses, pyogenic or amoebic, continue to be a problem both in the developed and under developed regions of the world. Though effective antibiotics and chemotherapeutics and image guided drainage modalities are easily available to the treating clinician today, the need for an early diagnosis in the face of non specific presentation remains a challenge.

\section{Conflicts of interest}

None identified.

\author{
RE F E R E N C E S
}

1. Johannsen EC, Sifri CD, Muzammil M. Infection of the liver: pyogenic liver abscess. Infect Dis Clin N Am. 2000;14:547-563.

2. Rahimian J, Wilson T, Oram V. Pyogenic liver abscesses; recent trends in etiology and mortality. Cin Infect Dis. 2004;39:1654-1659.

3. Matthews SB, Gertsch P, Baer HU. Hepatic abscesses after biliary tract procedures. SGO. 1990;170:469-475.

4. Malik AA, Bari SVL, Rouf KA, Wani KA. Pyogenic liver abscess: changing patterns and approach. World J Gastrointes Surg. 2010;2(12):395-401.

5. Huang SF, Ko CW, Chang CS. Liver abscess formation after transarterial chemoembolisation for malignant hepatic tumour. Hepatogastroenterology. 2003;50:1115-1118.

6. Wood TF, Rose DM, Chung M. Radiofrequency ablation of 231 unresectable hepatic tumours: indications, limitations and complications. Ann Surg Oncol. 2000;7:593-600.

7. Pearce NW, Knight R, Irving $H$, et al. Nonoperative management of pyogenic liver abscesses. HPB (Oxford). 2003;5:91-95.

8. Mohsen AH, Green ST, Read RC. Liver abscess in adults: a 10year experience in a UK centre. QJ Med. 2002;95:797-802.

9. Alvares Perez JA, Gonzalez JJ, Baldoneda RP. Single and multiple pyogenic liver abscesses: etiology, clinical course and outcome. Dig Surg. 2001;18:283-288.

10. Wong WM, Wong BC, Hui CK. Pyogenic liver abscess: retrospective analysis of 80 cases over a 10 - year period. $J$ Gastroenterol Hepatol. 2002;17:1001-1007.

11. Salahi R, Dehghani SM, Salahi H, Bahadur A, Abbasy HR, Salahi F. Liver abscess in children: a large single centre experience. Saudi J Gastroenterol. 2011;17(3):199-202.

12. DeRosier LC, Canon CM, Vickers SM. Liver abscess. In: Yeo CJ, ed. Shackelford's Surgery of the Alimentary Tract. 6th ed., vol. II. Philadelphia: Saunders; 2007: 1640-1658.

13. Jeffrey Jr RB, Tolentino CS, Chang SC. CT of small pyogenic abscess: the 'cluster sign'. AJR Am J Roentgenol. 1988;151:487-489.

14. Lee SH, Tomlinson C, Temple M, Amarol J, Connolly BL. Image guided percutaneous needle aspiration or catheter drainage of neonatal liver abscess: 14 year experience. AJR Am J Roentgenol. 2008;190:616-622.

15. Alvares Perez JA, Gonzalez JJ, Baldoneda RP. Clinical course, treatment and multivariate analysis of risk factors for pyogenic liver abscess. Am J Surg. 2001;181(2):177-186.

16. Mishra K, Basu S, Roychoudhry S, Kumar P. Liver abscess in children: an overview. World J Paed. 2010;6(3):210-216.

17. Mezhir JJ. Current management of pyogenic liver abscess: surgery is now second line treatment. J Am Coll Surg. 2010;210(6):975-983.

18. Yu SCH, Ho SSM, Lau WY. Treatment of pyogenic liver abscess: prospective randomized comparison of catheter drainage and needle aspiration. Hepatology. 2004;39:932-938.

19. Pang TC, Fung T, Samra T, Hugh TJ, Smith RC. Pyogenic liver abscess: an audit of 10 - year experience. World J

Gastroenterol. 2011;17(12):1622-1630. 
20. Tu JF, Huang XF, Hu RY, You XY, Zheng XF, Jiang FZ. Comparison of laparoscopic and open surgery for pyogenic liver abscess with biliary pathology. World J Gastroenterol. 2011;17(38):4339-4343.

21. Chen SC, Huang CC, Tsai SJ. Severity of disease as main predictor for mortality in patients in pyogenic lung abscesses. Am J Surg. 2009;198(2):164-172.

22. D'Angelica M, Fong Y. The liver. In: Townsend Jr CM, Beauchamp RD, Evers BM, Mattox KL, eds. Sabiston's Textbook of surgery. 18th ed., vol. II. Philadelphia: Saunders; 2008:1492.

23. Lodhi J, Sarwari AR, Muzammil M. Features distinguishing amoebic from pyogenic liver abscess: a review of 557 adult cases. Trop Med Int Health. 2004;9:718-723.

24. Wells CD, Arguedas M. Amoebic liver abscess. South Med J. 2004;97:673-682.

25. Hira PR, Iqbal J, Al - Ali F. Invasive amoebiasis: challenges in diagnosis in non endemic countries (Kuwait). Am J Trop Med Hyg. 2001;65:341-345.
26. Anees A, Khan MA, Zea MC, Pervez A, Khalid M. Amoebic liver abscess: the evolving concept of management. Internet $J \mathrm{Tr}$ Med. 2008;5(1).

27. Blessman J, Binh HD, Hung DM. Treatment of amoebic liver abscess with Metronidazole alone or in combination with ultra sound guided needle aspiration: a comparative, prospective randomized study. Trop Med Int Health. 2004;8:1030-1034.

28. McGau PL, Madiha TE, Thomson SR. Amoebic liver abscess: results of a conservative management policy. S Afr Med J. 2003;93:132-136.

29. Thomas PG. Amoebiasis and biliary infestation. In: Blumgart LH, ed. Surgery of the Liver and Biliary Tract. 2nd ed., vol. II. Edinburgh: Churchill Livingstone; 1994: 1888.

30. Sharma MP, Dasarathy S, Verma N. Prognostic markers in amoebic liver abscess: a prospective study. Am J Gastroenterol. 1996;91:2584-2588. 